\title{
INFECCIÓN URINARIA POR CORYNEBACTERIUM UREALYTICUM
}

\author{
M.A. REMACHA ESTERAS, J.M. GUERRA LASO*, A. ESTEBAN MARTÍN, \\ A. MORÁN BLANCO*
}

Servicio de Microbiología. *Medicina Interna. Hospital Monte San Isidro de León. León.

Actas Urol Esp. 28 (1): 75-76, 2004

\section{Sr. Director:}

Corynebacterium urealyticum es un bacilo gram-positivo de crecimiento lento, que forma parte de la flora cutánea de pacientes hospitalizados y/o inmunodeprimidos. Se han descrito infecciones graves por esta bacteria (endocarditis, bacteriemia, neumonía), pero ha sido en las últimas décadas cuando se le atribuye importancia como verdadero patógeno urinario ${ }^{1-6}$. La frecuencia de aislamiento en urocultivos es baja (0,025-0,32\%) según las series consultadas ${ }^{2-4}$.

Revisamos de forma retrospectiva las historias clínicas de 9 pacientes con infección del tracto urinario (ITU) por C. urealyticum. La infección predominó en varones ${ }^{7}$, con edad media de 83 años. Todos tenían enfermedad subyacente: EPOC $^{5}$, neoplasia ${ }^{2}$, demencia ${ }^{3}$, diabetes ${ }^{1}$. Seis pacientes tenían enfermedad urológica (adenocarcinoma de próstata, insuficiencia renal, ureterohidronefrosis, sindrome prostático $\left.{ }^{3}\right)$ y siete eran portadores de sonda urinaria (2 de ellos permanente). El 89\% de los pacientes habían recibido tratamientos antibióticos en los meses previos a la ITU y la clínica predominante fue la urológica (disuria, polaquiuria). $\mathrm{El} \mathrm{pH}$ de la orina resultó alcalino en el $78 \%$ de los casos. La evolución de los pacientes fue buena tras tratamiento antibiótico, y hubo 2 fallecimientos ajenos a la ITU (uno por deterioro multiorgánico y el otro por neumonía por aspiración).

Las muestras de orina se sembraron en agar sangre y CLED y la identificación del Corynebacterium spp. se realizó con el API Coryne (BioMérieux) y la prueba de urea rápida. La sensibilidad antibiótica se realizó por el método de difu- sión en disco de agar Mueller-Hinton con 5\% de sangre. Todos los aislados fueron sensibles a vancomicina, teicoplanina, tetraciclina, variables a las quinolonas y resistentes a beta-lactámicos y cotrimoxazol.

C. urealyticum fue descrito en 1985 como un patógeno urinario responsable de la cistitis incrustante ${ }^{5}$. También puede originar otros tipos de ITU: pielonefritis, cistitis no complicadas o bacteriuria asintomática ${ }^{3,4}$.

Presentamos 9 casos de ITU por C. urealyticum con factores de riesgo asociados con este tipo de infección, como ya han sido descritos en otra serie publicada por nuestro grupo ${ }^{1}$ : pacientes de edad avanzada con enfermedades crónicas, tratamiento antibiótico previo, hospitalización prolongada, cirugía y manipulación urológi$\mathrm{ca}^{2-6}$. Nuestros pacientes tenían una media de edad de 83 años con enfermedades crónicas (EPOC, diabetes, neoplasia, demencia), habían recibido tratamientos antibióticos previos y 7 eran portadores de sonda urinaria.

La patogenicidad de la bacteria se asocia a su fuerte actividad ureásica y la clínica es indistinguible al de otra ITU ${ }^{3,4,6}$.

El diagnóstico de infección urinaria por esta bacteria es difícil, ya que es considerada colonizante y necesita períodos de incubación prolongados. Son bacterias multirresistentes, por lo que el tratamiento antibiótico se hará en función del estudio de sensibilidad antibiótica ${ }^{3-6}$.

Aunque excepcional, ante una orina alcalina de un paciente con factores predisponentes y urocultivos negativos a las 24 horas de incubación, debemos considerar a C. urealyticum como un patógeno urinario y no como contaminante. 


\section{REFERENCIAS}

1. FERNÁNDEZ-NATAL I, GUERRA J, ALCOBA M, CACHÓN F, SORIANO F.: Bacteremia caused by multiply resistant Corynebacterium urealyticum: six case reports and review. Eur $J$ Clin Microbiol Infect Dis 2001; 20: 514-517.

2. ELCUAZ R, PERERA A, ÁlAMO I, NOGUERA F, LAFARGA B.: Infección del tracto urinario causada por Corynebacterium urealyticum. Enferm Infecc Microbiol Clin 1995; 13: 66-67.

3. NEBREDA-MAYORAL T, MUÑOZ-BELLIDO JL, GARCÍA-RODRÍGUEZ JA.: Incidence and characteristics of urinary tract infections caused by Corynebacterium urealyticum (Corynebacterium group D2). Eur J Clin Microbiol Infect Dis 1994; 13: 600-604.

4. AGUADO JM, PONTE C, SORIANO F.: Bacteriuria with a multiply resistant species of Corynebacterium (Corynebacterium group D2): an unnoticed cause of urinary tract infection. J Infect Dis 1987; 156: 144150.
5. SORIANO F, PONTE C, SANTAMARÍA M, AGUADO JM, WILHELMI I, VELA R et al.: Corynebacterium group D2 as a cause of alkaline encrusted cystitis: report of four cases and characterization of the organism. J Clin Microbiol 1985; 21: 788-792.

6. GARCÍA DIEZ F, FERNÁNDEZ-NATAL I, GUERREIRO R, GONZÁLEZ DEL VALLE C.: Corynebacterium D2 como germen ureolítico: a propósito de cinco casos. Arch Esp de Urol 1991; 44: 1069-1072.

Dra. M.A. Remacha Esteras

(Laboratorio Microbiología)

Hospital Monte San Isidro

Ctra. Asturias, s/n

24008 León

(Trabajo recibido el 21 abril de 2003) 